\title{
Surveillance of emerging drugs of abuse in Hong Kong: validation of an analytical tool
}

\author{
Magdalene HY Tang, CK Ching, ML Tse, Carol Ng, Caroline Lee, YK Chong, Watson Wong, \\ Tony WL Mak *; Emerging Drugs of Abuse Surveillance Study Group
}

\section{A B S T R A C T}

Objective: To validate a locally developed chromatography-based method to monitor emerging drugs of abuse whilst performing regular drug testing in abusers.

Design: Cross-sectional study.

Setting: Eleven regional hospitals, seven social service units, and a tertiary level clinical toxicology laboratory in Hong Kong.

Participants: A total of 972 drug abusers and high-risk individuals were recruited from acute, rehabilitation, and high-risk settings between 1 November 2011 and 31 July 2013. A subset of the participants was of South Asian ethnicity. In total, 2000 urine or hair specimens were collected.

Main outcome measures: Proof of concept that surveillance of emerging drugs of abuse can be performed whilst conducting routine drug of abuse testing in patients.

Results: The method was successfully applied to 2000 samples with three emerging drugs of abuse detected in five samples: PMMA (paramethoxymethamphetamine),

TFMPP

[1-(3-trifluoromethylphenyl)piperazine], and methcathinone. The method also detected conventional drugs of abuse, with codeine,

This article was published on $10 \mathrm{Mar}$ 2015 at www.hkmj.org. methadone, heroin, methamphetamine, and ketamine being the most frequently detected drugs.

Asians had significantly higher rates of using opiates such as heroin, methadone, and codeine; and that ketamine and cocaine had significantly higher detection rates in acute subjects compared with the rehabilitation population.

Conclusions: This locally developed analytical method is a valid tool for simultaneous surveillance of emerging drugs of abuse and routine drug monitoring of patients at minimal additional cost and effort. Continued, proactive surveillance and early identification of emerging drugs will facilitate prompt clinical, social, and legislative management.

\section{Hong Kong Med J 2015;21:114-23}

DOI: $10.12809 / \mathrm{hkmj} 144398$

${ }^{1}$ MHY Tang, PhD
${ }^{1}$ CK Ching, FRCPA, FHKAM (Pathology)
${ }^{2}$ ML Tse, FHKCEM, FHKAM (Emergency Medicine)
${ }^{3}$ C Ng, BSW, MA
${ }^{1}$ C Lee, MSc
${ }^{1}$ YK Chong, MB, BS
${ }^{1}$ W Wong, MSc
${ }^{1}$ TWL Mak *, FRCPath, FHKAM (Pathology)
for the Emerging Drugs of Abuse Surveillance Study Group (Group
members are listed in the Appendix)
${ }^{1}$ Toxicology Reference Laboratory, Hospital Authority, Hong Kong
${ }^{2}$ Hong Kong Poison Information Centre, Hospital Authority, Hong Kong
${ }^{3}$ Hong Kong Lutheran Social Service, the Lutheran Church - Hong Kong
Synod, Homantin, Hong Kong
* Corresponding author: makwl@ha.org.hk

New knowledge added by this study

A locally developed method is a valid tool for monitoring the penetrance of emerging drugs of abuse into our society whilst performing regular drugs of abuse testing.

Implications for clinical practice or policy

- Implementation of the analytical method in the routine drug monitoring of drug abusers will enable simultaneous surveillance of novel drugs of abuse at minimal extra cost and effort.

- Continued and proactive surveillance of emerging drugs of abuse in the population will facilitate prompt measures in the clinical, social, and legislative management of these constantly changing and potentially dangerous drugs.

\section{Introduction}

Despite continuous efforts, drug abuse remains a major social and medical problem in today's society. In particular, there has been a rapid and continued growth of 'emerging' drugs of abuse (DOA) on a global scale. ${ }^{1,2}$ Emerging DOA, also called designer drugs or novel psychoactive substances, bear a chemical and/ or pharmacological resemblance to conventional DOA and pose a threat to public health, but are often (initially) not controlled by law. They are easily accessible from street dealers or through the internet, and are often presumed to be safer than conventional 
DOA owing to their 'legal' or 'herbal' nature. ${ }^{1,3}$ In Hong Kong, the drug scene has also been penetrated in recent years by such substances as the piperazine derivative TFMPP [1-(3-trifluoromethylphenyl) piperazine ${ }^{4}{ }^{4}$ the synthetic cannabinoids, ${ }^{5}$ the methamphetamine derivative PMMA (paramethoxymethamphetamine), ${ }^{6}$ and the NBOMe $(\mathrm{N}$ methoxybenzyl derivatives of phenethylamine). ${ }^{7}$ Some of these novel drugs pose a significant health threat and numerous fatalities have been reported worldwide. ${ }^{8-10}$ In particular, PMMA and the NBOMe drugs have been associated with severe clinical toxicity and fatalities in Hong Kong., 6

Effective diagnosis and treatment of emerging DOA intoxication rely on the timely and accurate detection of these substances. Whilst immunoassay and drug screening methods are well-established for conventional DOA, laboratory analysis of novel drugs is not so readily available. This inevitably leads to the delayed discovery of emerging drugs and consequently early medical and social intervention is compromised. Recently, a liquid chromatographytandem mass spectrometry (LC-MS/MS)-based method has been established locally that allows the simultaneous detection of 47 commonly abused drugs in addition to over 45 emerging DOA and their metabolites in urine ${ }^{11}$ and hair (the latter manuscript in preparation). The aim of the current study was to validate this analytical method as a tool to monitor emerging DOA whilst performing regular DOA testing by applying the method to 2000 urine and hair specimens collected from drug abusers as well as high-risk individuals.

\section{Methods}

\section{Sample collection}

Between 1 November 2011 and 31 July 2013, 964 urine and 1036 hair specimens $(n=2000$ in total) were collected for analysis. Subjects who were included in the study were patients/clients of the units listed, and who were suspected to be actively using DOA and who agreed to participate in the study: (i) substance abuse clinics within the Hospital Authority (Castle Peak Hospital, Kowloon Hospital, Kwai Chung Hospital, Pamela Youde Nethersole Eastern Hospital, Prince of Wales Hospital, Queen Mary Hospital); (ii) accident and emergency (A\&E) departments within the Hospital Authority (Pamela Youde Nethersole Eastern Hospital, Pok Oi Hospital, Princess Margaret Hospital, Queen Mary Hospital, Tuen Mun Hospital, United Christian Hospital, Yan Chai Hospital); (iii) the Hong Kong Poison Information Centre (HKPIC) toxicology clinic; (iv) counselling centres for psychotropic substance abusers (CCPSA; Evergreen Lutheran Centre, Rainbow Lutheran Centre, Cheer Lutheran Centre); (v) various rehabilitation centres including the Society of Rehabilitation and Crime

\section{香港新興毒品的監察：一種分析方法的驗證 鄧萱然、程楚君、謝萬里、吳雪琴、李婉慧、張耀君、 黃華生、麥永禮}

目的：驗證本地研發的色譜測量方法作為一種於濫藥者進行定期毒品 測試時, 同時調查新興毒品的工具。

\section{設計：橫斷面研究。}

安排：香港十一所分區醫院、七個社會福利機構及一間專科臨床毒理 學化驗室。

參與者：2011年11月1日至2013年7月 31 日期間共招募972位參與 者, 當中包括急症、復康及高危人士。部份參與者為南亞裔。此研究 共收集二千個尿液或頭髮樣本。

\section{主要結果測量 : 驗證於進行定期毒品測試時同時監察新興毒品的概} 念。

結果：測量方法成功應用於二千個樣本的分析, 並於五個樣本中驗出 三類新興毒品，包括PMMA、TFMPP及methcathinone。測量方法同 時檢測出傳統毒品, 當中以可待因、美沙酮、海洛英、甲基安非他命 及氯胺酮最為普遍。研究亦發現南亞裔人士較多使用鴉片類藥物如海 洛英、美沙酮及可待因。另外, 於急診患者中檢測出氯胺酮及可卡因 亦較復康人士普遍。

結論：這個本地研發的測量方法是一個用於同時進行定期毒品測試和 檢測新興毒品的有效及低成本工具。持續並主動的監察有助早期識別 新出現的毒品, 並有利於讯速採取相應的臨床、社會和立法管理措 施。

Prevention (SRACP), Operation Dawn and Caritas Wong Yiu Nam Centre; and (vi) Youth Outreach. Pregnant women and individuals aged under 18 years were excluded from the study. The majority of the participants were Chinese, although those recruited from SRACP were exclusively South Asians.

The study was approved by the institutional ethics review boards (Kowloon West Cluster: KW/ FR-11-011 (41-05); Kowloon Central/Kowloon East Cluster: KC/KE-11-0170/ER-2; Hong Kong West Cluster: UW 11-398; Hong Kong East Cluster: HKEC2011-068; New Territories West Cluster: NTWC/ CREC/989/11; New Territories East Cluster: CRE2011.427). Subjects donated samples on a voluntary basis and informed consent was obtained. Each subject donated either urine or hair, or both, at each donation episode. Some gave repeated sample(s): donations were at least 8 weeks apart. Urine was collected in a plain plastic bottle and frozen until analysis. For hair, a lock of hair was collected from the back of the head for analysis. The root end was identified to facilitate segmental analysis.

\section{Sample analysis}

The methodology for urine analysis has been detailed in a separate publication. ${ }^{11}$ In brief, the urine sample was subjected to an initial glucuronidase digestion, followed by solid phase extraction and sample 
TABLE I. The conventional and emerging drugs of abuse being analysed for

\begin{tabular}{|c|c|}
\hline Drug class & Drug (or metabolite) \\
\hline \multirow[t]{17}{*}{ Amphetamines } & 4-Fluoroamphetamine ${ }^{\star}$ \\
\hline & 4-Methylthioamphetamine ${ }^{\star}$ \\
\hline & Amphetamine \\
\hline & Bromo-DragonFly* \\
\hline & Chloroamphetamine* \\
\hline & $\mathrm{DOB}^{*}$ \\
\hline & $\mathrm{DOET}^{*}$ \\
\hline & $\mathrm{DOM}^{*}$ \\
\hline & HMMA \\
\hline & $\mathrm{MBDB}^{*}$ \\
\hline & MDA \\
\hline & MDEA* \\
\hline & MDMA \\
\hline & Methamphetamine \\
\hline & $\mathrm{N}$-ethylamphetamine* \\
\hline & $\mathrm{PMA}^{*}$ \\
\hline & PMMA $^{*}$ \\
\hline \multirow[t]{6}{*}{ Opiates } & Codeine \\
\hline & Codeine M (nor) \\
\hline & Heroin \\
\hline & Heroin M (6-MAM) \\
\hline & Morphine \\
\hline & Morphine M (nor) \\
\hline \multirow[t]{4}{*}{ Cocaine and metabolites } & Cocaine \\
\hline & Cocaine M (benzoylecgonine) \\
\hline & Cocaine M (cocaethylene) \\
\hline & Cocaine M (nor) \\
\hline \multirow{4}{*}{$\begin{array}{l}\text { Ketamine and metabolites/ } \\
\text { analogues }\end{array}$} & Ketamine \\
\hline & Ketamine M (nor) \\
\hline & Methoxetamine ${ }^{*}$ \\
\hline & Tiletamine ${ }^{*}$ \\
\hline \multirow{14}{*}{$\begin{array}{l}\text { Benzodiazepines and } \\
\text { metabolites }\end{array}$} & Chlordiazepoxide \\
\hline & Diazepam \\
\hline & Diazepam M (nor) \\
\hline & Estazolam \\
\hline & Flunitrazepam \\
\hline & Flunitrazepam M (7-amino) \\
\hline & Midazolam \\
\hline & Midazolam M (1-OH) \\
\hline & Midazolam M (4-OH) \\
\hline & Nimetazepam \\
\hline & Oxazepam \\
\hline & Temazepam \\
\hline & Triazolam \\
\hline & Triazolam M (1-OH) \\
\hline
\end{tabular}

Abbreviation: $M=$ metabolite

* Emerging drugs of abuse
TABLE I. (cont'd)

\begin{tabular}{|c|c|}
\hline Drug class & Drug (or metabolite) \\
\hline \multirow[t]{8}{*}{ Cannabinoids } & Cannabis M (carboxy-THC) \\
\hline & Cannabis M (THC-OH) \\
\hline & JWH-018* \\
\hline & JWH-018 M (4-OH-indole) ${ }^{\star}$ \\
\hline & JWH-018 M (N-5-OH-pentyl) \\
\hline & JWH-073* \\
\hline & CP- $47,497^{\star}$ \\
\hline & C8 homologue of CP-47,497 \\
\hline \multirow[t]{7}{*}{ Phenethylamines } & $2 \mathrm{C}-\mathrm{B}^{\star}$ \\
\hline & $2 \mathrm{C}-\mathrm{H}^{*}$ \\
\hline & $2 \mathrm{C}-\mathrm{I}^{*}$ \\
\hline & 2C-T-2* \\
\hline & $2 \mathrm{C}-\mathrm{T}-4^{*}$ \\
\hline & $2 \mathrm{C}-\mathrm{T}-7^{*}$ \\
\hline & Mescaline* \\
\hline \multirow[t]{6}{*}{ Piperazines } & $\mathrm{BZP}^{*}$ \\
\hline & $\mathrm{mCPP}^{*}$ \\
\hline & $\mathrm{MDBP}^{*}$ \\
\hline & pFPP* \\
\hline & $\mathrm{pMeOPP}^{*}$ \\
\hline & TFMPP* \\
\hline \multirow[t]{6}{*}{ Cathinones } & Cathinone* \\
\hline & Ethylone $^{*}$ \\
\hline & Mephedrone* \\
\hline & Methcathinone $^{\star}$ \\
\hline & Methedrone* \\
\hline & Methylone* \\
\hline \multirow[t]{5}{*}{ Tryptamines } & 5-MeO-DIPT* \\
\hline & Alpha-methyltryptamine* \\
\hline & Bufotenine $^{*}$ \\
\hline & Dimethyltryptamine ${ }^{\star}$ \\
\hline & Psilocin* \\
\hline \multirow{3}{*}{$\begin{array}{l}\text { Miscellaneous (emerging } \\
\text { drugs of abuse) }\end{array}$} & $\mathrm{MDPV}^{*}$ \\
\hline & Mitragynine ${ }^{*}$ \\
\hline & Salvinorin $A^{*}$ \\
\hline \multirow{14}{*}{$\begin{array}{l}\text { Miscellaneous (conventional } \\
\text { drugs of abuse) }\end{array}$} & Dextromethorphan \\
\hline & $\begin{array}{l}\text { Dextromethorphan M } \\
\text { (dextrorphan) }\end{array}$ \\
\hline & LSD \\
\hline & LSD M (nor) \\
\hline & LSD M (OH) \\
\hline & Methadone \\
\hline & Methadone M (EDDP) \\
\hline & Methaqualone \\
\hline & Phentermine \\
\hline & Zolpidem \\
\hline & Zopiclone \\
\hline & Amobarbital \\
\hline & Butabarbital \\
\hline & Secobarbital \\
\hline
\end{tabular}


concentration. The hair sample (first 3-cm segment) was first decontaminated and subsequently subjected to simultaneous micro-pulverisation and extraction in solvent. The final filtrates were analysed by LC-MS/MS performed on an Agilent 6430 triple-quadrupole mass spectrometer (Agilent Technologies, Singapore) coupled with Agilent 1290 Infinity liquid chromatography system. The 47 conventional and 47 emerging DOA identified for analysis are listed in Table 1 . The analytical method had previously been validated according to international guidelines. ${ }^{12}$

\section{Statistical analysis}

Statistical analysis was performed using Fisher's exact test, with a P value of less than 0.05 considered statistically significant. Comparison of the drug detection rates was made between (i) different ethnic groups and (ii) samples collected in the rehabilitation and acute settings.

\section{Results}

\section{Subject demographics}

In total, 972 individuals took part in the study (720 males, 252 females). Their respective mean and median age was 35 and 33 years (range, 18-74 years). Of the 972 subjects, 815 were single-time donors and 157 donated repeated samples (between 2 and 6 donations each). There were 1224 donation episodes (815 from single-time donors; 409 from repeated donors) and 2000 specimens collected in total, of which 964 were urine and 1036 were hair (Fig 1). Of the 1224 donation episodes, the subjects were recruited from: substance abuse clinics $(n=822)$, drug rehabilitation and counselling centres $(n=320)$, youth hangout centre $(n=41)$, HKPIC toxicology clinic $(n=28)$, and A\&E departments $(n=13)$.

\section{Emerging drugs of abuse}

In the 2000 specimens analysed, five specimens were found to contain three emerging DOAs: PMMA, TFMPP, and methcathinone. A methamphetamine derivative, PMMA, was detected in three hair specimens (cases 1-3, Table 2). All three hair samples

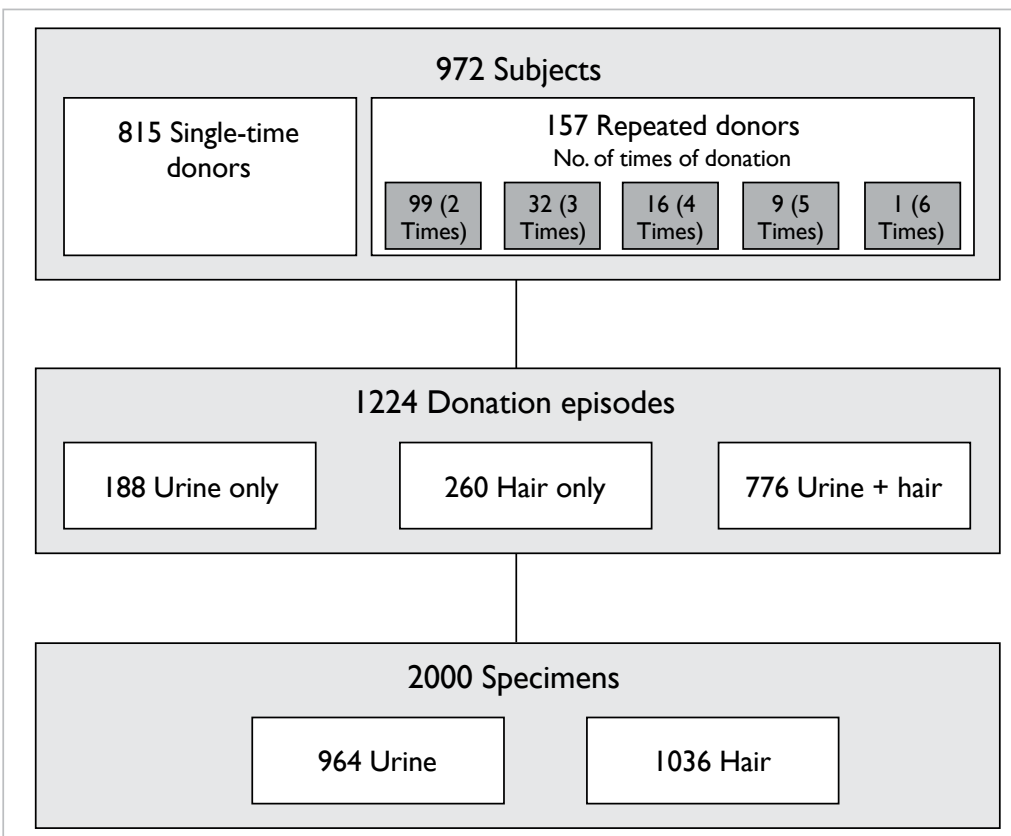

FIG I. Subject demographics

TABLE 2. Emerging drugs of abuse detected in the study

\begin{tabular}{|c|c|c|c|c|}
\hline Case No. & Sex/age (years) & Setting & Drugs detected in hair & Drugs detected in urine \\
\hline 1 & $M / 28$ & A\&E & $\begin{array}{l}\text { PMMA } \\
\text { Cocaine and metabolite } \\
\text { Ketamine and metabolite }\end{array}$ & $\begin{array}{l}\text { Cocaine metabolite } \\
\text { Ketamine and metabolite }\end{array}$ \\
\hline 2 & $\mathrm{M} / 45$ & SAC & $\begin{array}{l}\text { PMMA } \\
\text { Amphetamine } \\
\text { Methamphetamine } \\
\text { Cocaine and metabolites } \\
\text { Ketamine and metabolite } \\
\text { Zolpidem }\end{array}$ & $\begin{array}{l}\text { Methamphetamine } \\
\text { Cocaine and metabolite } \\
\text { Ketamine and metabolite } \\
\text { Phentermine }\end{array}$ \\
\hline 3 & $M / 28$ & Drug rehabilitation centre & $\begin{array}{l}\text { PMMA } \\
\text { Cocaine and metabolites } \\
\text { Ketamine and metabolite }\end{array}$ & $\begin{array}{l}\text { Ketamine and metabolite } \\
\text { Cannabis metabolite }\end{array}$ \\
\hline 4 & $\mathrm{~F} / 26$ & HKPIC toxicology clinic & $\begin{array}{l}\text { Cocaine } \\
\text { Ketamine }\end{array}$ & $\begin{array}{l}\text { TFMPP } \\
\text { Cocaine metabolite } \\
\text { Ketamine and metabolite }\end{array}$ \\
\hline 5 & $\mathrm{~F} / 27$ & SAC & (Hair not collected) & $\begin{array}{l}\text { Methcathinone } \\
\text { Amphetamine } \\
\text { Methamphetamine } \\
\text { HMMA (metabolite of amphetamine-like substances) } \\
\text { Cocaine metabolite }\end{array}$ \\
\hline
\end{tabular}

Abbreviations: A\&E = accident and emergency department; HKPIC = Hong Kong Poison Information Centre; PMMA = paramethoxymethamphetamine; SAC = substance abuse clinic;TFMPP $=1$-(3-Trifluoromethylphenyl)piperazine 
were also found to contain cocaine and ketamine. Nonetheless, PMMA was not detected in the subjects' concurrent urine sample.

A piperazine derivative, TFMPP, was detected in one urine specimen (case 4, Table 2), together with cocaine and ketamine. Nonetheless TFMPP was not detected in the parallel hair sample.

Methcathinone, also known as ephedrone, is a cathinone (beta-keto amphetamine) analogue. It was detected in combination with amphetamine, methamphetamine, and cocaine metabolite in one urine specimen (case 5, Table 2). No parallel hair specimen was available from this subject.
Conventional drugs of abuse

Analysis of the 964 urine samples revealed the presence of 19 types of conventional DOA (Fig 2a). Codeine was the most common, being detected in $47 \%$ of the urine samples, followed by methadone (35\%), heroin (22\%), methamphetamine (21\%), ketamine (20\%), zopiclone (20\%), amphetamine (17\%), midazolam (17\%), and dextromethorphan (14\%). Cocaine and cannabis were detected in $6 \%$ and $3 \%$ of urine samples, respectively.

In hair specimens (1036 in total), 14 types of conventional DOA were detected (Fig 2b). Codeine (36\%) and methadone (35\%) were the most

(a)

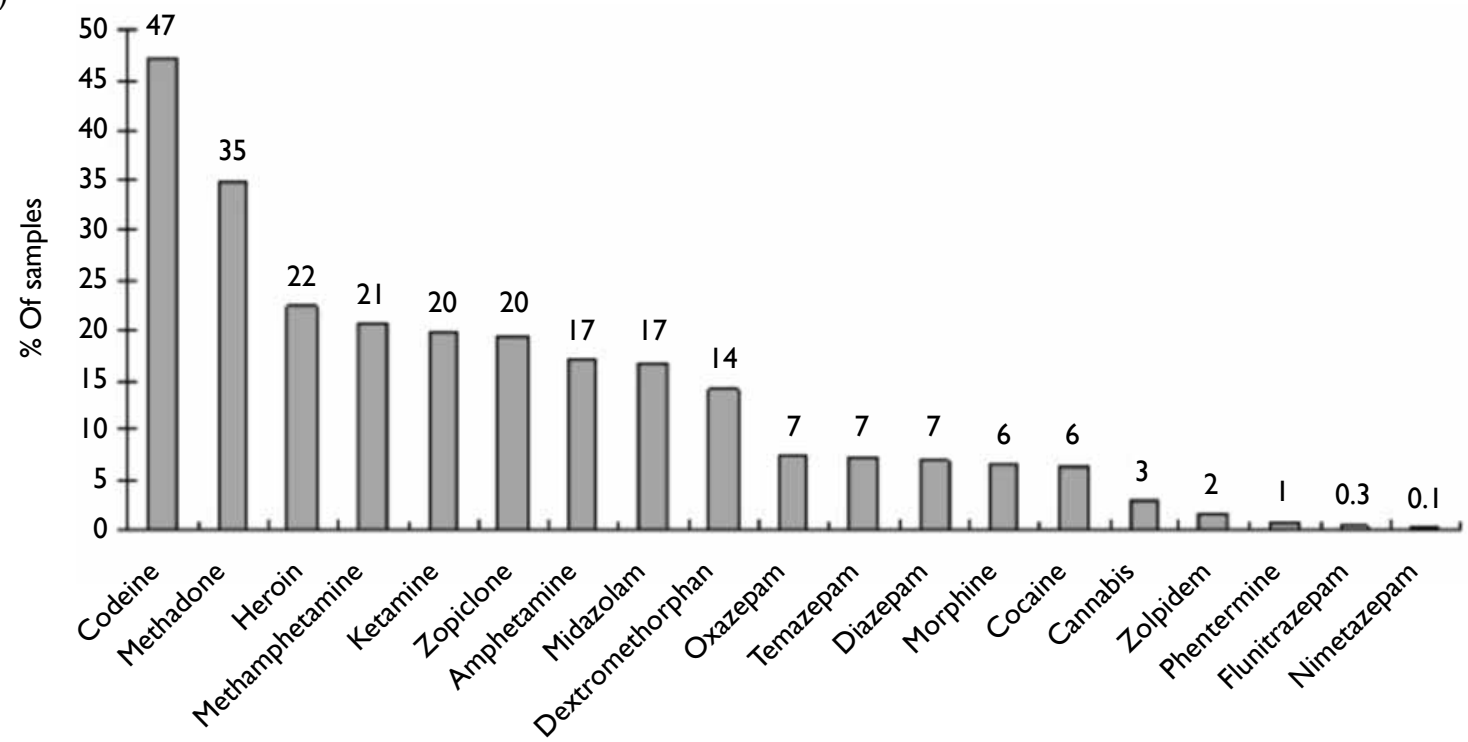

(b)

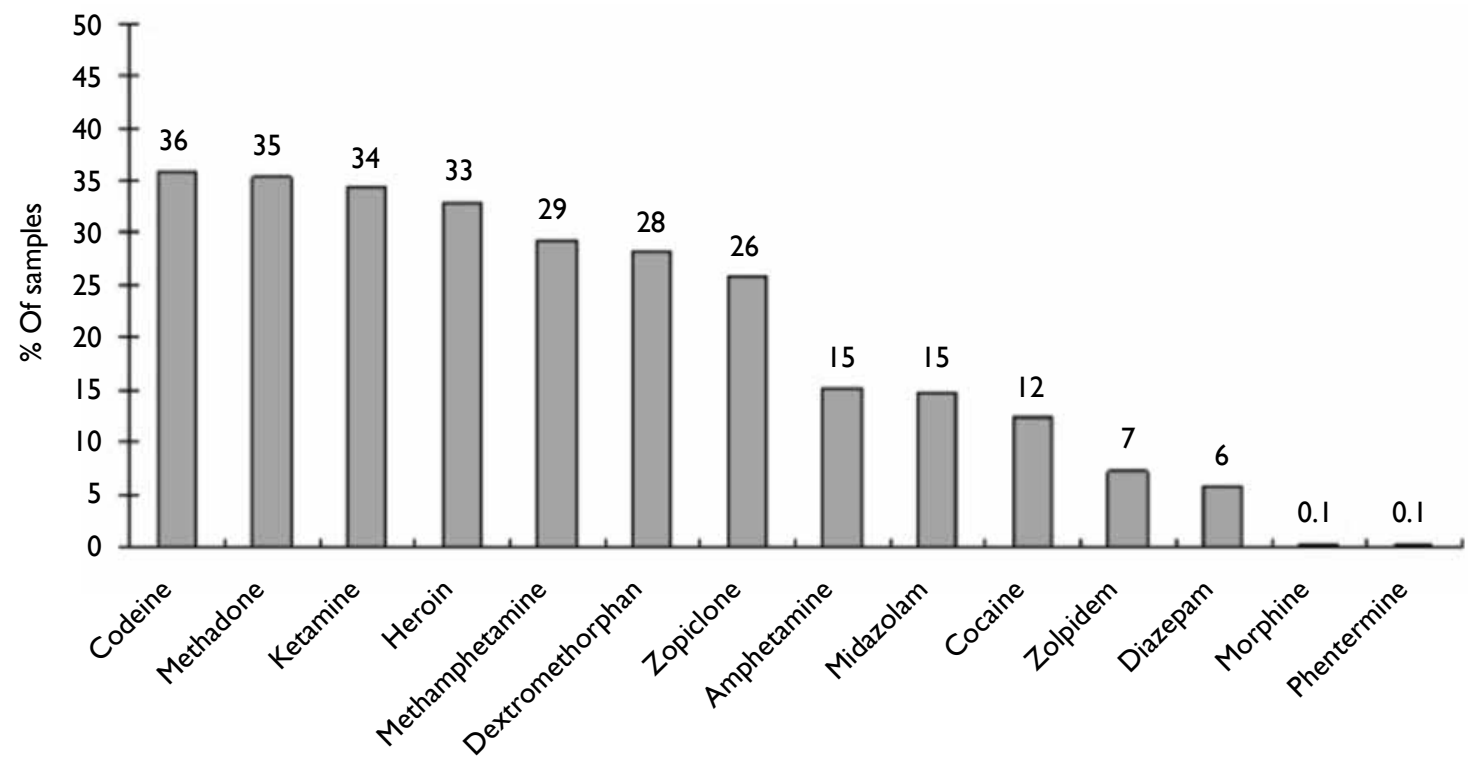

FIG 2. Conventional drugs of abuse detected in (a) urine and (b) hair samples as a percentage of the total number of samples collected (964 urine and 1036 hair samples) 
prevalent, followed by ketamine $(34 \%)$, heroin $(33 \%), \quad$ ketamine, zopiclone, and diazepam $(\mathrm{P}<0.001)$ as well methamphetamine $(29 \%)$, dextromethorphan $(28 \%)$, as cocaine and amphetamine $(\mathrm{P}<0.05)$ were detected and zopiclone (26\%). Cocaine and zolpidem were at significantly higher rates in Chinese compared detected in $12 \%$ and $7 \%$ of the samples, respectively.

\section{Ethnic minority}

A subset of participants $(n=130)$ were of South Asian ethnicity. These subjects donated 248 specimens in 130 episodes. Their drug use pattern was significantly different to that of Chinese. Comparison of urinalysis results revealed that South Asians had a significantly higher proportion of opiate use such as heroin, methadone, and codeine $(\mathrm{P}<0.001)$ as well as dextromethorphan $(\mathrm{P}<0.05$; Fig $3 \mathrm{a})$. On the contrary, with South Asians. Analysis of hair specimens showed a largely similar pattern of discrepancy between the two ethnicities (Fig 3b).

\section{Collection site setting}

The urine samples in the current study were collected from different settings: 38 samples from acute setting (A\&E departments and HKPIC toxicology clinic); 885 samples from drug rehabilitation setting (substance abuse clinics, CCPSA and other rehabilitation centres); and 41 from a high-risk population (youth

(a)

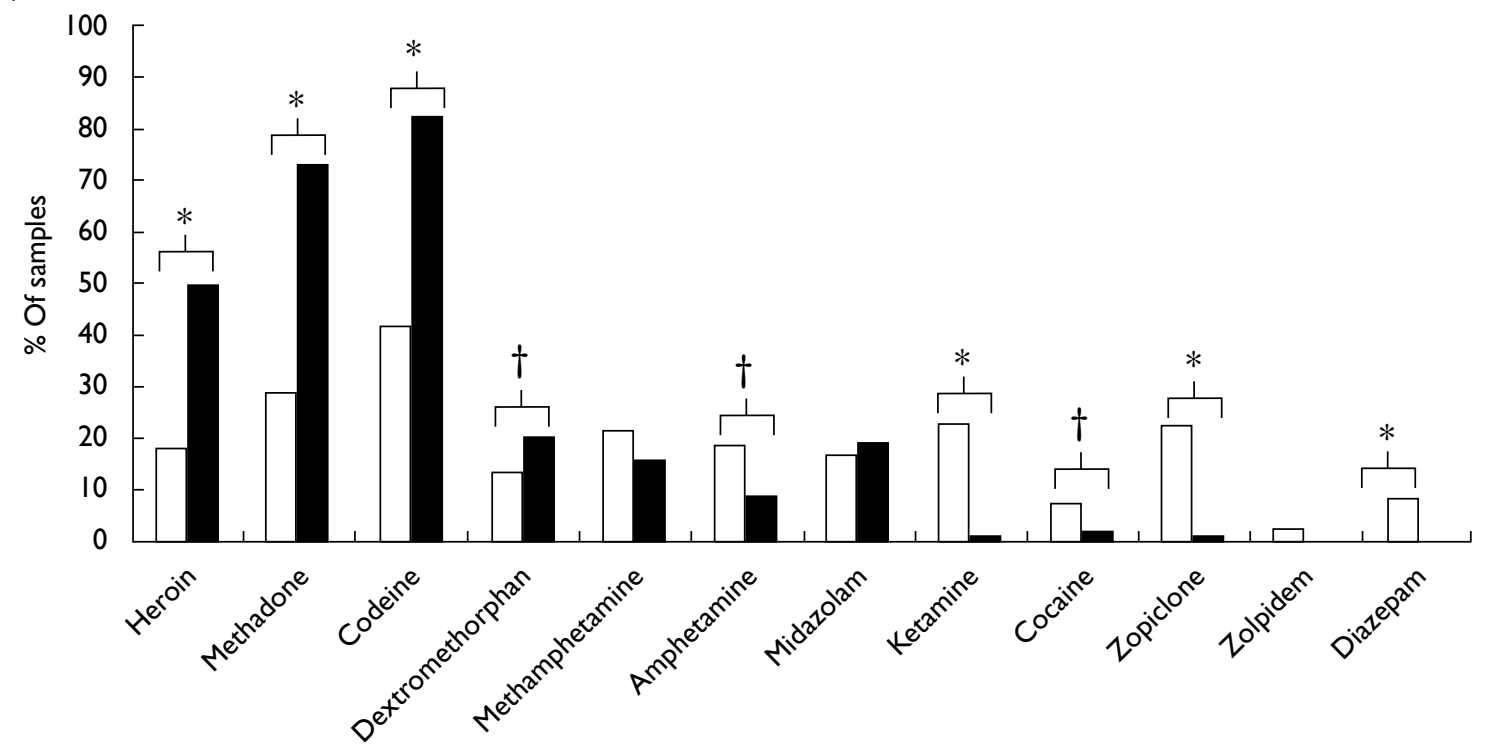

(b)

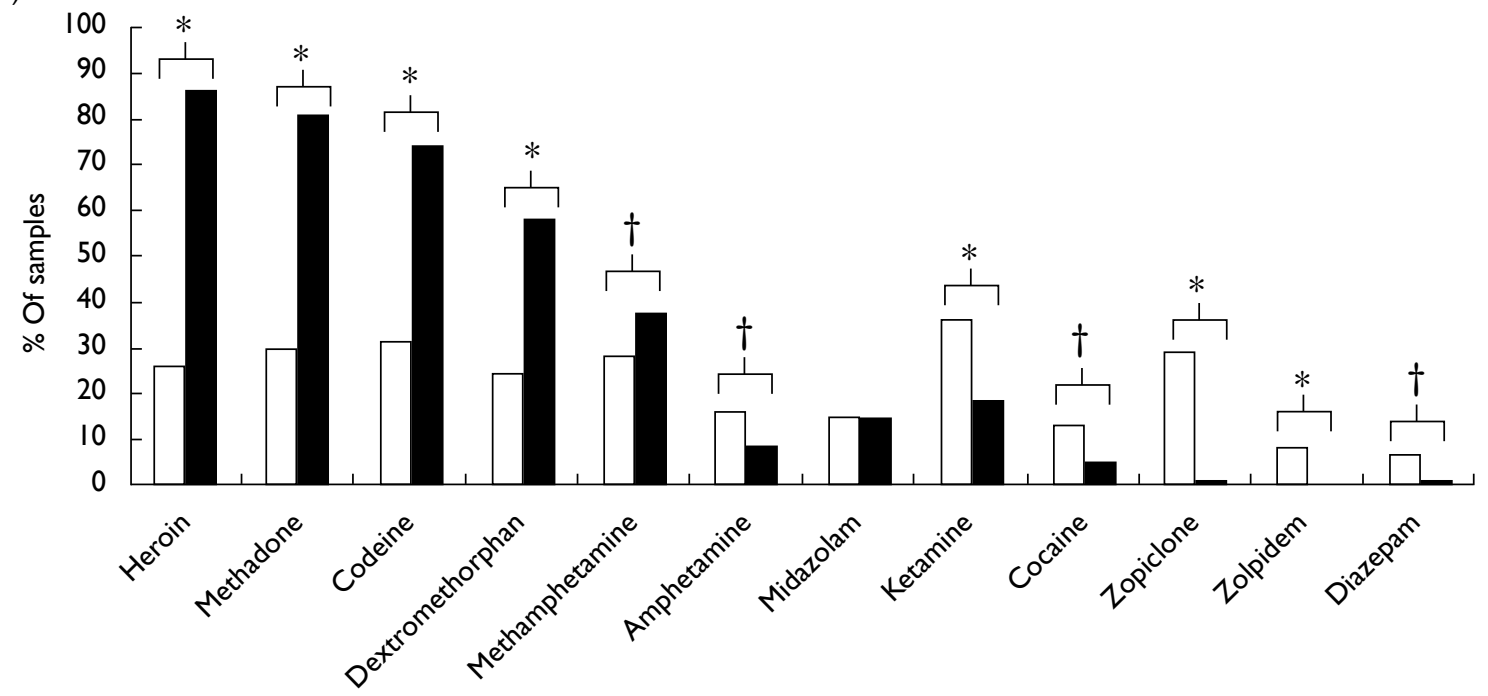

FIG 3. Comparison of the drugs detected in (a) urine and (b) hair samples collected from Chinese (white bars) and South Asians (dark bars)

* $P<0.001$

$+\mathrm{P}<0.05$ but $\geq 0.005$ 
hangout). A comparison of drugs detected between the acute and rehabilitation settings revealed a significantly higher detection rate of ketamine and cocaine $(\mathrm{P}<0.001)$ in the former (Fig 4). Drugs such as codeine, methadone, heroin, zopiclone, and dextromethorphan were detected at higher rates in samples collected in a rehabilitation setting.

\section{Discussion}

Emerging DOA are constantly being monitored worldwide by agencies such as the European Monitoring Centre for Drugs and Drug Addiction (EMCDDA). In 2008, 13 emerging DOA were reported for the first time to EMCDDA; by 2012, 73 new drugs had been reported within a year. ${ }^{1}$ Recent years have also seen the emergence of such designer drugs in Hong Kong, some of which have caused severe morbidity and fatalities. ${ }^{4,5,7}$ The early identification of emerging drugs enables prompt counteractive measures in terms of their clinical and social management, and the surveillance of emerging drugs in the population is increasingly being adopted globally as a proactive approach to combat drug abuse. ${ }^{13-15}$ In view of this, the present study was conducted to validate a locally developed LC-MS/MS method to screen for emerging DOA in the local population whilst simultaneously monitoring routine DOA. The study was conducted over a 21-month period. Multiple clinical and social service units from across the city collaborated in the study for a wider geographical coverage and more representative results. In 2013, approximately 10069 drug abusers were reported in Hong Kong. ${ }^{16}$ This study population (972 subjects) was estimated to represent $9.7 \%$ of the total potential subjects. Regarding the response or participation rate, due to practical concerns and limited manpower, it was not possible for every collaborating unit to document fully the number of subjects approached or the number who refused consent.

The current results revealed the presence of three emerging drugs (PMMA, TFMPP, and methcathinone) in five specimens. This low prevalence is an expected finding due to the intrinsic nature of 'emerging' rather than 'established' drugs. Nevertheless, PMMA is a highly toxic methamphetamine derivative that has been sold on the drug market as MDMA (3,4-methylenedioxymethamphetamine) substitute. ${ }^{8}$ The drug has been reported to have caused up to 90 fatalities worldwide over the years, including eight fatalities in Taiwan..$^{8,17}$ In particular, PMMA-associated fatalities have also been reported recently in Hong Kong. ${ }^{6}$

On the other hand, TFMPP is a piperazine derivative with mild hallucinogenic effects and, when taken with another piperazine derivative benzylpiperazine (BZP), causes ecstasy-like effects. ${ }^{18}$ Piperazine derivatives are known to cause dissociative and sympathomimetic toxicity. ${ }^{19}$ The drug TFMPP was first reported in Hong Kong in $2010^{4}$ and has been identified as an emerging drug in Ireland in recent years. ${ }^{15}$



FIG 4. Comparison of the drugs detected in urine samples collected under the rehabilitation (white bars) and acute (dark bars) settings

* $P<0.001$

$\dagger P<0.05$ but $\geq 0.005$ 
Another emerging DOA detected in the study, methcathinone, gained popularity from the 1970 s to 1990 s, and was recently reported as a 'reemerging' DOA in Sweden. ${ }^{14}$ It is an amphetaminelike stimulant and is among a group of synthetic cathinone compounds, commonly known as "bath salts", that have been associated with numerous fatalities worldwide. ${ }^{20}$ Other highly toxic cathinone derivatives include mephedrone and MDPV (methylenedioxypyrovalerone), ${ }^{9,10}$ both of which are also covered in the analytical method but were not detected in the current study.

Of the conventional DOA, the opiates, methamphetamine, and ketamine were among the most frequently detected in this study. This is consistent with the data on reported drug abusers that was published by the local Central Registry of Drug Abuse. ${ }^{21}$ Since this manuscript focuses on screening for emerging DOA, detailed analysis of conventional drug use such as gender and age differences was not performed. However, an interesting finding was the observation that significantly higher proportions of South Asian drug abusers used opiates such as heroin, methadone, and codeine compared with Chinese; Chinese drug abusers were much more likely to use ketamine, cocaine, zopiclone, and diazepam. This highlights the ethnic differences in drug use and indicates that alternative approaches may be required for the clinical and social management of ethnic minorities in Hong Kong.

It is of interest to note the particularly high percentage of ketamine and cocaine detected in urine samples collected at A\&E departments and toxicology clinic compared with the other collection sites. This may indicate that these drugs carry a more acute and severe toxicity profile relative to the other drugs with a consequent need of hospitalisation. A previous study on drug driving in Hong Kong also reported ketamine as the most prevalent drug detected in driver casualties who presented to the A\&E department. ${ }^{22}$ Comparison of hair analysis results was not made here, since the main focus was on the difference between acute and non-acute cases; hair specimens would be less helpful since this biological matrix does not reflect recent exposure to drugs (see below for further discussion).

The present study showed a broadly similar pattern in urine and hair matrices in terms of the conventional DOA detected. Cocaine, dextromethorphan, and zolpidem were detected at higher rates in hair compared with urine, and may indicate the relatively high deposition efficiency of these drugs in hair matrix. It should be noted, however, that the metabolites of zolpidem were not included in the current assay, and may decrease its sensitivity for detection in urine. Urine and hair specimens have different 'detection windows', that is, they reflect different time frames of drug intake.
Detection in urine indicates recent intake (within hours/days); thus this matrix is useful for the management of acute toxicity and drug overdose. The detection window of hair is much longer (weeks/months), enabling this matrix to be used for monitoring long-term drug use or abstinence.

When interpreting the results of the current study, it should be noted that some drugs may have been taken for therapeutic reasons, for example codeine, methadone, phentermine, or the tranquilizers/benzodiazepines. It was not possible in this study to differentiate medical use from abuse. It should also be noted that some drugs may be present as metabolites of others, for example temazepam and oxazepam (both of which are diazepam metabolites) and the emerging drug mCPP (metabolite of the antidepressant trazodone). Morphine is also the metabolite of codeine and heroin; it was only reported here as a drug in the absence of either codeine or heroin in the same sample.

Effective control of novel drugs depends on their early identification. A number of means to monitor emerging DOA have been proposed, such as conducting population surveys, analysing online test purchases, or wastewater analysis. ${ }^{3}$ Population surveys suffer the potential drawback of obtaining inaccurate data, since the actual identity of the drugs may differ from the claimed ingredients, for example, BZP being sold as 'MDMA' tablets. ${ }^{23}$ Analysing drug items purchased online is a costly approach due to the vast number of products available. Wastewater analysis may be used for monitoring conventional DOA, but the approach may not be easily adapted to the surveillance of emerging drugs due to the anticipated minute levels (ng/L range) in wastewater. ${ }^{24}$ All the above approaches require a considerable amount of financial and manpower resources. We propose the integration of emerging DOA surveillance into the routine drug monitoring of patients using the established analytical method. This surveillance approach is accurate, readily attainable, and is also achieved with minimal extra cost and effort since it is a convenient by-product of the routine drug monitoring of patients. Additionally, its applicability in A\&E department patients allows the early identification of highly toxic novel drugs.

The proposed analytical method is LC-MS/ MS-based, and offers several advantages over traditional DOA testing by immunoassay methods. First, development of an immunoassay is a lengthy process (in terms of years) involving the generation of antibodies. Immunoassay analysis also depends solely on the availability of commercial kits. These features do not favour early detection of new compounds given the protean nature of emerging drugs. In contrast, LC-MS/MS-based methods are much more versatile, permitting in-house enhancement of the method to allow detection of 
new compounds as soon as they enter the market. Second, although immunoassay methods require minimal capital investment, their running costs are high due to the generation of antibodies. On the other hand, LC-MS/MS methods require a high initial investment in analysers, but the running cost is lower in the long term as the reagents involved are relatively inexpensive. Lastly, unlike immunoassay methods that are only preliminary in nature and require further confirmatory testing, mass spectrometry analysis is already confirmatory with accurate and definitive results.

In addition to laboratory analysis, the emerging DOA surveillance team requires the expertise of medical doctors to keep a close watch on emerging drugs on the market, especially those with high clinical toxicity. Based on this 'toxico-intelligence', scientists should then enhance the analytical method to include such emerging substances. Hence, the effective control of emerging drugs will require a team of trained medical doctors and scientists, as well as versatile technology that enables the continual expansion of analytical coverage. In view of the resource requirements, specialised toxicology centres may be better suited for the purpose.

The present study has proven the concept that a locally developed analytical method is a valid tool to monitor emerging DOA whilst simultaneously performing regular DOA testing in patients. Implementation of the method in the routine drug monitoring of abusers will enable the continued and proactive surveillance of novel drugs in the population with minimal extra cost and effort. This surveillance gathers important information so that society can be prepared in terms of legislation, as well as social and clinical management of these potentially dangerous drugs. Further expansion of the analytical coverage will help keep abreast of the rapid and constant change in the designer drug scene.

\section{Acknowledgements}

This study was financially supported by the Beat Drugs Fund (Narcotics Division, Security Bureau of the HKSAR Government), project reference BDF101021. The authors are also grateful to all participants and for the generous assistance received from participating clinical divisions within the Hospital Authority and social service units.

\section{Declaration}

No conflicts of interests were declared by authors.

\section{Appendix}

\section{Members of the Emerging Drugs of Abuse Surveillance Study Group:}

\footnotetext{
${ }^{1}$ YH Lam, MPhil

${ }^{2}$ WH Cheung, FHKCPsych, FHKAM (Psychiatry)
}

${ }^{3}$ Eva Dunn, FHKCPsych, FHKAM (Psychiatry)

${ }^{3}$ CK Wong, FHKCPsych, FHKAM (Psychiatry)

${ }^{4} \mathrm{YC}$ Lo, MSc, FIBMS

${ }^{5}$ M Lam, FHKCPsych, FHKAM (Psychiatry)

${ }^{6}$ Michael Lee, MSc

${ }^{7}$ Angus Lau, MSW

${ }^{8}$ Albert KK Chung, FHKCPsych, FHKAM (Psychiatry)

${ }^{9}$ Sidney Tam, FHKCPath, FHKAM (Pathology)

${ }^{10}$ Ted Tam, BSW

${ }^{11}$ Vincent Lam, BA(Hon)

${ }^{12}$ Hezon Tang, MSW

${ }^{13}$ Katy Wan, BSocSc, MA

${ }^{14}$ Mamre Lilian Yeh, BA, MSc

${ }^{15}$ MT Wong, FHKCPsych, FHKAM (Psychiatry)

${ }^{16}$ CC Shek, FHKCPath, FHKAM (Pathology)

${ }^{17}$ WK Tang, MD, FHKAM (Psychiatry)

${ }^{18}$ Michael Chan, FRCPA, FHKAM (Pathology)

${ }^{19}$ Jeffrey Fung, FRCSEd, FHKAM (Emergency Medicine)

${ }^{20} \mathrm{SH}$ Tsui, FRCP (Edin), FHKAM (Emergency Medicine)

${ }^{21}$ Albert Lit, FCEM, FHKAM (Emergency Medicine)

${ }^{22}$ Joe Leung, FHKCEM, FHKAM (Emergency Medicine)

1 Toxicology Reference Laboratory, Hospital Authority, Hong Kong

2 Substance Abuse Assessment Unit, Kwai Chung Hospital, Hong Kong

3 Department of Psychiatry, Pamela Youde Nethersole Eastern Hospital, Hong Kong

4 Department of Pathology, Pamela Youde Nethersole Eastern Hospital, Hong Kong

5 Department of General Adult Psychiatry, Castle Peak Hospital, Hong Kong

${ }^{6}$ Department of Clinical Pathology, Tuen Mun Hospital, Hong Kong

7 The Society of Rehabilitation and Crime Prevention, Hong Kong

8 Department of Psychiatry, Queen Mary Hospital, Hong Kong

9 Department of Pathology and Clinical Biochemistry, Queen Mary Hospital, Hong Kong

${ }^{10}$ Youth Outreach, Hong Kong

${ }^{11}$ Evergreen Lutheran Centre, Hong Kong Lutheran Social Service, the Lutheran Church - Hong Kong Synod

${ }^{12}$ Cheer Lutheran Centre, Hong Kong Lutheran Social Service, the Lutheran Church - Hong Kong Synod

${ }^{13}$ Rainbow Lutheran Centre, Hong Kong Lutheran Social Service, the Lutheran Church - Hong Kong Synod

${ }^{14}$ Operation Dawn Ltd (Gospel Drug Rehab Centre), Hong Kong

${ }^{15}$ Department of Psychiatry, Kowloon Hospital, Hong Kong

${ }^{16}$ Department of Pathology, Queen Elizabeth Hospital, Hong Kong

${ }^{17}$ Department of Psychiatry, the Chinese University of Hong Kong, Hong Kong 
${ }^{18}$ Department of Chemical Pathology, Prince of Wales Hospital, Hong Kong

${ }^{19}$ Accident and Emergency Department, Tuen Mun Hospital, Hong Kong

${ }^{20}$ Accident and Emergency Department, Queen Mary Hospital, Hong Kong

${ }^{21}$ Accident and Emergency Department, Princess Margaret Hospital, Hong Kong

${ }^{22}$ Accident and Emergency Department, Pamela Youde Nethersole Eastern Hospital, Hong Kong

\section{References}

1. European Monitoring Centre for Drugs and Drug Addiction (EMCDDA), Europol. New drugs in Europe, 2012. EMCDDA-Europol 2012 Annual Report on the implementation of Council Decision 2005/387/JHA; 2012.

2. Nelson ME, Bryant SM, Aks SE. Emerging drugs of abuse. Emerg Med Clin North Am 2014;32:1-28.

3. Brandt SD, King LA, Evans-Brown M. The new drug phenomenon. Drug Test Anal 2014;6:587-97.

4. Poon WT, Lai CF, Lui MC, Chan AY, Mak TW. Piperazines: a new class of drug of abuse has landed in Hong Kong. Hong Kong Med J 2010;16:76-7.

5. Tung CK, Chiang TP, Lam M. Acute mental disturbance caused by synthetic cannabinoid: a potential emerging substance of abuse in Hong Kong. East Asian Arch Psychiatry 2012;22:31-3.

6. The first mortality case of PMMA in Hong Kong. 本港首 次發現服用毒品PMMA後死亡個案. RTHK. 2014 Feb 4. http://m.rthk.hk/news/20140204/982353.htm.

7. Tang MH, Ching CK, Tsui MS, Chu FK, Mak TW. Two cases of severe intoxication associated with analytically confirmed use of the novel psychoactive substances 25B-NBOMe and 25C-NBOMe. Clin Toxicol (Phila) 2014;52:561-5.

8. Lin DL, Liu HC, Yin HL. Recent paramethoxymethamphetamine (PMMA) deaths in Taiwan. J Anal Toxicol 2007;31:109-13.

9. Maskell PD, De Paoli G, Seneviratne C, Pounder DJ. Mephedrone (4-methylmethcathinone)-related deaths. J Anal Toxicol 2011;35:188-91.

10. Durham M. Ivory wave: the next mephedrone? Emerg Med J 2011;28:1059-60.

11. Tang MH, Ching CK, Lee CY, Lam YH, Mak TW. Simultaneous detection of 93 conventional and emerging drugs of abuse and their metabolites in urine by UHPLCMS/MS. J Chromatogr B Analyt Technol Biomed Life Sci
2014;969:272-84

12. The fitness for purpose of analytical methods: A laboratory guide to method validation and related topics. EURACHEM Working Group; 1998.

13. Archer JR, Dargan PI, Hudson S, Wood DM. Analysis of anonymous pooled urine from portable urinals in central London confirms the significant use of novel psychoactive substances. QJM 2013;106:147-52.

14. Helander A, Beck O, Hägerkvist R, Hultén P. Identification of novel psychoactive drug use in Sweden based on laboratory analysis-initial experiences from the STRIDA project. Scand J Clin Lab Invest 2013;73:400-6.

15. O’Byrne PM, Kavanagh PV, McNamara SM, Stokes SM. Screening of stimulants including designer drugs in urine using a liquid chromatography tandem mass spectrometry system. J Anal Toxicol 2013;37:64-73.

16. Newly/previously reported drug abusers by sex. Central Registry of Drug Abuse. Available from: http://www.nd.gov. hk/statistics_list/doc/en/t11.pdf. Accessed 3 Feb 2015.

17. European Monitoring Centre for Drugs and Drug Addiction (EMCDDA). EMCDDA risk assessments: Report on the risk assessment of PMMA in the framework of the joint action on new synthetic drugs; 2003.

18. Arbo MD, Bastos ML, Carmo HF. Piperazine compounds as drugs of abuse. Drug Alcohol Depend 2012;122:174-85.

19. Wood DM, Button J, Lidder S, Ramsey J, Holt DW, Dargan PI. Dissociative and sympathomimetic toxicity associated with recreational use of 1-(3-trifluoromethylphenyl) piperazine (TFMPP) and 1-benzylpiperzine (BZP). J Med Toxicol 2008;4:254-7.

20. Zawilska JB, Wojcieszak J. Designer cathinones-an emerging class of novel recreational drugs. Forensic Sci Int 2013;231:42-53.

21 . Reported drug abusers by sex by common type of drugs abused. Central Registry of Drug Abuse. Available from: http://www.nd.gov.hk/statistics_list/doc/en/t15.pdf. Accessed 11 Jul 2014.

22. Wong OF, Tsui KL, Lam TS, et al. Prevalence of drugged drivers among non-fatal driver casualties presenting to a trauma centre in Hong Kong. Hong Kong Med J 2010;16:246-51.

23. Wood DM, Dargan PI, Button J, et al. Collapse, reported seizure-and an unexpected pill. Lancet 2007;369:1490.

24. van Nuijs AL, Gheorghe A, Jorens PG, Maudens K, Neels $\mathrm{H}$, Covaci A. Optimization, validation, and the application of liquid chromatography-tandem mass spectrometry for the analysis of new drugs of abuse in wastewater. Drug Test Anal 2014;6:861-7. 